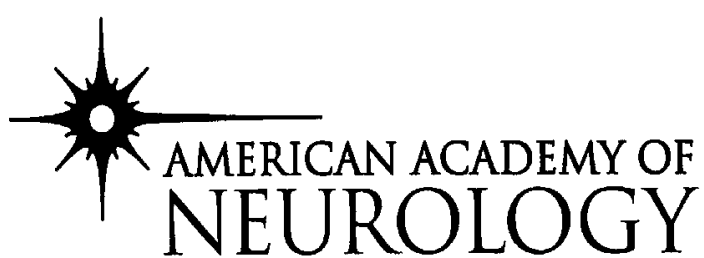

\title{
PRACTICE PARAMETER: THYMECTOMY FOR AUTOIMMUNE MYASTHENIA GRAVIS (AN EVIDENCE-BASED REVIEW)
}

\author{
Report of the Quality Standards Subcommittee of the American Academy of Neurology
}

Gary S. Gronseth, MD; and Richard J. Barohn, MD

\begin{abstract}
The Quality Standards Subcommittee of the American Academy of Neurology is charged with developing practice parameters for neurologists for diagnostic procedures, treatment modalities, and clinical disorders. The selection of topics for which practice parameters are used is based on prevalence, frequency of use, economic impact, membership involvement, controversy, urgency, external constraints, and resources required. This paper addresses the role of thymectomy in the treatment of nonthymomatous autoimmune MG.

In 1939, Blalock et al. ${ }^{1}$ reported the remission of generalized MG in a 21-year-old woman after removal of a cystic thymic tumor. Subsequently, Blalock et al. ${ }^{2,3}$ performed thymectomy on MG patients without thymoma, found hyperplasia in the thymus glands, and reported improvement in at least half of their patients. Since these reports, thymectomy, with or without the presence of thymoma, has gained widespread acceptance as a form of treatment for MG.

Because a definitive study of the effectiveness of thymectomy has never been done, ${ }^{4,5}$ the role of thymectomy in the management of MG remains uncertain. Nevertheless, physicians have to advise their patients regarding the benefits of thymectomy based on the existing literature. Our goal is to develop evidence-basedrecommendations for clinicians considering thymectomy for patients with nonthymomatous autoimmune MG by performing a systematic review and analysis of the literature.
\end{abstract}

Process. Identification and selection of studies. We searched the National Library of Medicine's Medline database from 1966 to February 1998 using the medical subject headings "myasthenia gravis" (restricted to the surgery subheading) and "thymectomy." To identify articles published before 1966, or missed by our original search strategy, we reviewed the references of the identified articles.

We classified the resulting articles into the following categories: Class II, controlled but nonrandomized studies describing outcomes in MG patients with and without thymectomy; and Class III, uncontrolled case series describing outcomes in patients with or without thymectomy.

Within a given controlled (Class II) study, we planned to describe the therapeutic effect of thymectomy by comparing the rate MG patients receiving thymectomy achieved desirable outcomes with the rate MG patients not receiving thymectomy achieved desirable outcomes. The nonrandomized nature of Class II studies often introduces differences in the baseline characteristics of the thymectomy and nonthymectomy patient groups that can effect MG outcomes independent of thymectomy. To the extent possible, we planned to adjust for these confounding differences in baseline prognostic characteristics. In the absence of randomized controlled trials, such adjustments are critical for estimating the actual therapeutic effect, if any, of thymectomy. ${ }^{6}$

Between uncontrolled (Class III) studies, comparisons of outcome rates in thymectomy and nonthymectomy MG patients introduce additional confounding baseline differences. ${ }^{6}$ These additional confounders include institutional, geographic, and historical variations that potentially impact MG patient outcomes independent of thymectomy. Because these additional confounders are difficult to identify and adjust for, outcome comparisons between uncontrolled studies are particularly unreliable. ${ }^{7}$ For this reason, we excluded Class III studies from further consideration.

Abstracted study characteristics. From the controlled studies describing outcomes we abstracted the following characteristics: method and setting of cohort assembly, years during which patients were enrolled in the cohort, number of subjects assembled, duration of follow-up, proportion of subjects lost to follow-up, and the thymectomy techniques employed.

From the American Academy of Neurology, St. Paul, MN.

Approved by the AAN Quality Standards Subcommittee October 9, 1999. Approved by the Practice Committee January 15, 2000. Approved by the AAN Board of Directors February 26, 2000.

Received January 11, 1999. Accepted in final form January 20, 2000.

Address correspondence and reprint requests to the Quality Standards Subcommittee of the American Academy of Neurology, 1080 Montreal Avenue, St. Paul, MN 55116.

Copyright $(2000$ by AAN Enterprises, Inc. 
Because of reported associations with MG outcomes, we also extracted the following study population characteristics: proportion of patients younger than 50 years at the time of diagnosis of $\mathrm{MG}$, proportion of female patients, proportion of patients with more severe MG at the time of diagnosis (defined by Osserman's grade $2 \mathrm{~b}, 3$, or $4^{8}$ ), and the proportion of patients with strictly ocular myasthenia at the time of diagnosis.

Thymectomy in patients with thymoma has benefits other than MG treatment. ${ }^{1}$ Therefore, we excluded patients with thymomas from the analysis.

Measures of association between thymectomy and outcome. In reviewing each study we considered the following MG outcomes: survival (taking into account perioperative mortality), improvement since diagnosis, asymptomatic on or off medication, and asymptomatic off medication (i.e., medication-free remission).

Ideally, controlled studies of thymectomy in MG patients report outcomes using time-to-outcome (survival) techniques. ${ }^{9}$ Survival techniques account for the differences in the duration of follow-up and changes in outcomes over time. Unfortunately, most controlled studies of thymectomy in MG simply report the proportion, or crude rate, of patients achieving an outcome over the study's follow-up period. Crude outcome rates vary with the duration of follow-up of the study. Within a given study, however, crude outcome rates of the thymectomy and nonthymectomy patient groups can be compared when the patient groups have similar follow-up durations.

To compare the crude rates within a given controlled study, we calculated the relative rate by dividing the thymectomy patient group's crude rate of achieving the outcome by the nonthymectomy patient group's crude rate of achieving the outcome using the formula presented in table 1.

We also calculated the $95 \%$ CI of these relative rates. Calculation of the relative outcome rates in this manner compensates for differences in follow-up duration between controlled studies, and allows the analysis of the results of all controlled thymectomy MG studies.

In studies providing sufficient information, we recalculated the relative rates of outcomes after controlling for potential confounding variables of age, gender, and severity of myasthenia. We used Wilcoxon's test to determine significance of the changes in relative rates measured after controlling for these variables.

Analysis. Study characteristics. Our Medline search strategy identified 310 articles discussing MG and thymectomy. Review of these articles and their references identified 28 articles describing outcomes in 21 MG cohorts. ${ }^{10-37}$ These controlled studies described outcomes in MG patients treated with and without thymectomy. We graded all studies Class II because none allocated subjects randomly to thymectomy or nonthymectomy management.

Table 2 summarizes the characteristics of these studies. Publication years ranged from 1953 to 1998 . Articles describing the same cohort are grouped in the same row. The article by Beghi et al. ${ }^{15}$ describes a subset of the cohort of Mantegazza et al. ${ }^{17}$ The matched cohort of Buckingham et al. ${ }^{27}$ likely included subjects described initially by Eaton and Clagett. $^{35}$

Authors assembled cohorts from MG patients referred to tertiary care centers or neuromuscular clinics. The only population-based study was by Christensen et al. ${ }^{10}$ The study described by Mantegazza et al. ${ }^{17}$ likely included the majority of MG patients seen in Italy. Investigators acquired subjects over several years, often over several decades. Some of the studies included patients with strictly ocular MG.

As mentioned previously MG patients were not allocated randomly to thymectomy or nonthymectomy treatment groups. Additionally, no study described formal selection criteria for MG patients undergoing thymectomy (e.g., the presence or absence of thymic hyperplasia during preoperative evaluations.)

Many studies did not describe the thymectomy technique employed. The majority of the studies reporting the thymectomy technique used the transsternal approach. Subjects in the cohorts described by Beghi et al. ${ }^{15}$ Mantegazza et al., ${ }^{17}$ Papatestas et al., ${ }^{20}$ and Perlo et al. ${ }^{29}$ underwent either transsternal or transcervical thymectomies.

Follow-up, when described, varied from an average of 3 to 28 years. Within each cohort, investigators reported comparable follow-up periods in the thymectomy and nonthymectomy groups. Most studies failed to mention the number of patients lost to follow-up. Reported losses varied from 0 to $33 \%$.

Authors obtained data, including outcome information, from periodic examinations, retrospective chart review, or mailed and telephone surveys. No author described blinded assessments of outcomes.

Authors used nonstandard definitions of remission. The majority required the absence of MG symptoms or signs. Some studies allowed mild restricted, fixed residual weakness. The cohorts described by Henson et al. ${ }^{33}$ and Simpson ${ }^{34}$ defined remission as the ability to do a full day's work. Most investigators did not describe a minimal asymptomatic period necessary to define remission. Beghi et al., ${ }^{15}$ Mantegazza et al., ${ }^{17}$ and Evoli et al. ${ }^{11,14}$ required patients to have no symptoms or signs for at least 1 year to be considered in remission. 
Positive associations between thymectomy and improved outcomes. The relative rates of attaining a desired outcome in MG patients receiving and not receiving thymectomy are listed in table 3 and are illustrated in the figure. Table 3 additionally lists for each study the percentage of patients who attained a desired outcome (crude rate).

With the exceptions of the cohorts described by Evoli et al., ${ }^{14}$ Werneck et al., ${ }^{13}$ and Grob et al., ${ }^{21}$ the relative rates indicate that MG patients undergoing thymectomy were more likely to achieve medication-free remission, become asymptomatic, and improve than MG patients not undergoing thymectomy (see the figure). The 1996 study by Evoli et al. ${ }^{14}$ was severely underpowered. In contrast to other studies, none of the nonthymectomy patients of Werneck et al. ${ }^{13}$ had severe MG (Osserman grade 3 or 4). This difference could have suppressed a thymectomy benefit because patients with severe MG have a poorer prognosis than MG patients with less severe disease. ${ }^{15,20,25}$ The article by Grob et al. ${ }^{21}$ provided

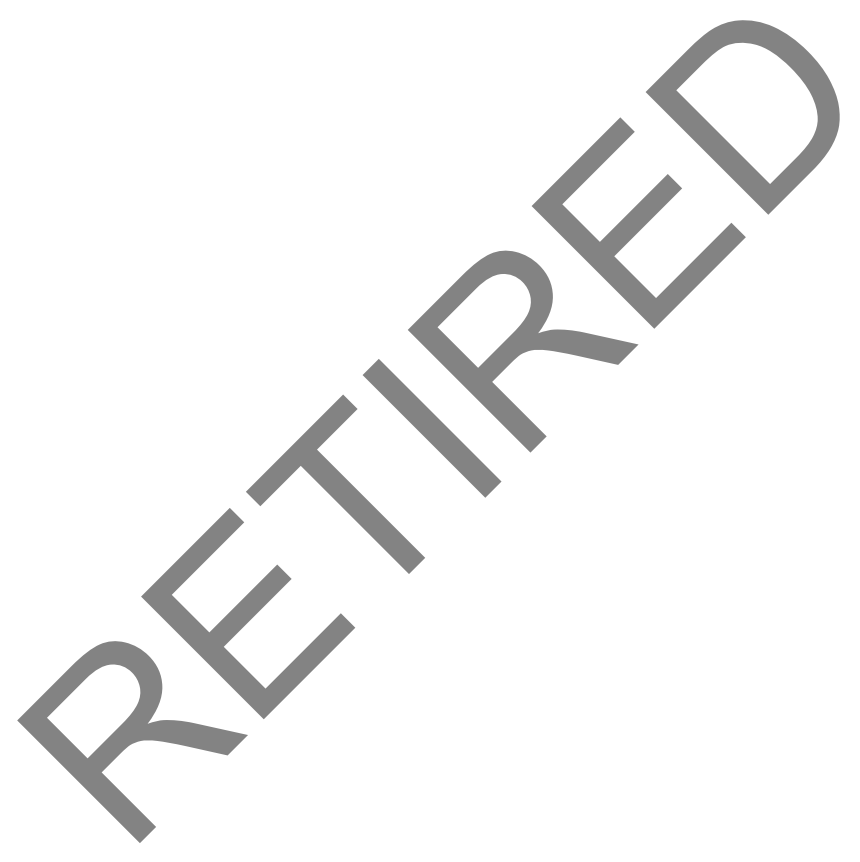


Table 2 Characteristics of cohort surveys comparing outcomes in MG patients with and without thymectomy (TY)

\begin{tabular}{|c|c|c|c|c|c|c|c|c|c|}
\hline $\begin{array}{l}\text { Author pub year* } \\
\text { (inception years) }\end{array}$ & Cohort assembly setting & Group & $\mathrm{n}$ & $\begin{array}{l}\text { Follow-up, y; } \\
\text { (median) } \\
\text { [range] }\end{array}$ & $\begin{array}{c}\text { Lost to } \\
\text { follow-up, } \\
\% \\
\end{array}$ & $\begin{array}{l}<51 \text { y at } \\
\text { diagnosis, } \\
\% \\
\end{array}$ & $\begin{array}{c}\text { Female, } \\
\%\end{array}$ & $\begin{array}{c}\text { Severe, } \dagger \\
\%\end{array}$ & $\begin{array}{c}\text { Ocular, } † \\
\%\end{array}$ \\
\hline Christensen et al. $^{10}$ & Epidemiologic study of MG in & All & 212 & 9.2 & 0 & - & - & 38 & 11 \\
\hline \multirow[t]{2}{*}{1998} & \multirow{2}{*}{$\begin{array}{l}\text { western Denmark } 1975 \text { to } 1989 \text {, } \\
\text { mortality only outcome measured }\end{array}$} & $\mathrm{TY}$ & 94 & - & - & - & - & 52 & - \\
\hline & & No TY & 118 & - & - & - & - & 25 & - \\
\hline \multirow{3}{*}{$\begin{array}{l}\text { Evoli et al. } \\
1998\end{array}$} & \multirow{3}{*}{$\begin{array}{l}\text { Generalized } \mathrm{MG},<45 \text { years old at } \\
\text { onset, matched for gender, age at } \\
\text { onset, severity, FU }\end{array}$} & All & 65 & 14.8 & 0 & 100 & 75 & 42 & 0 \\
\hline & & TY & 45 & 15.3 & - & - & 78 & 38 & - \\
\hline & & No TY & 20 & 13.6 & - & - & 70 & 50 & - \\
\hline Beekman et al. ${ }^{12}$ & Consecutive patients referred to & All & 84 & 9.6 & 0 & 70 & 63 & - & 9.5 \\
\hline \multirow[t]{2}{*}{$1997(1985-1989)$} & \multirow{2}{*}{ University Hospital } & TY & 44 & {$[>3]$} & - & 100 & - & - & 0 \\
\hline & & No TY & 40 & - & - & 38 & - & - & 35 \\
\hline Werneck et al. ${ }^{13}$ & \multirow{3}{*}{$\begin{array}{l}\text { Matched TY and no TY patients } \\
\text { for gender, age at onset, duration, } \\
\text { FU, treatment }\end{array}$} & All & 60 & - . & - & - & 67 & 48 & 0 \\
\hline \multirow[t]{2}{*}{1996} & & TY & 30 & 6.3 & - & - & 67 & 53 & - \\
\hline & & No TY & 30 & 5.3 & - & - & 67 & 43 & - \\
\hline \multirow{3}{*}{$\begin{array}{l}\text { Evoli et al. }{ }^{14} \\
1996\end{array}$} & \multirow{3}{*}{$\begin{array}{l}\text { Retrospective assembly age }>40, \\
\text { generalized MG }\end{array}$} & All & 80 & {$[>2]$} & - & 0 & - & 56 & 0 \\
\hline & & TY & 41 & - & - & - & - & 63 & - \\
\hline & & No TY & 39 & - & - & - & - & 51 & - \\
\hline Beghi et al. ${ }^{15,16}$ & \multirow{3}{*}{$\begin{array}{l}\text { Record review of patients referred } \\
\text { to three Italian neuromuscular } \\
\text { centers }\end{array}$} & All & 844 & 5.3 & - & 71 & 64 & 51 & 13 \\
\hline \multirow{2}{*}{$1991(1973-1987)$} & & TY & 544 & - & - & 80 & 69 & 55 & 9 \\
\hline & & No TY & 290 & - & - & 55 & 55 & 43 & 21 \\
\hline Mantegazza et al. ${ }^{17,18}$ & Record review of patients referred & All & 1125 & 4.9 & & 74 & 64 & 54 & 12 \\
\hline 1990 & to six Italian neuromuscular & TY & 812 & - & - & 82 & 68 & 59 & 7 \\
\hline & centers & No TY & 313 & - & - & 54 & 54 & 41 & 26 \\
\hline Donaldson et al. ${ }^{19}$ & Record review neuromuscular & All & 165 & & & 67 & 57 & 59 & 39 \\
\hline $1990(1975-1988)$ & clinic, Colorado Thymoma 11\% & TY & 108 & & & 79 & 76 & - & - \\
\hline & & No TY & 57 & & & 46 & 21 & - & - \\
\hline Papatestas et al. ${ }^{20}$ & Patients with MG registered at Mt. & All & 1836 & & & - & - & 36 & 16 \\
\hline $1987(1951-1985)$ & Sinai Medical Center, NY & TY & & & - & 74 & - & 40 & 0.3 \\
\hline & & No TY & & - & - & - & - & 33 & 28 \\
\hline Grob et al. ${ }^{21-23}$ & Record review MG patients & All & 253 & 18 & - & - & 57 & - & 14 \\
\hline $1987(1940-1985)$ & referred to 1,000 -bed hospital and & & & & - & - & - & - & - \\
\hline & its clinics & & & - & - & - & - & - & - \\
\hline Scadding et al. ${ }^{24}$ & MG patients at hospital, excluded & & & {$[>5]$} & 5 & - & - & - & - \\
\hline $1985(1942-1976)$ & steroid/aza treated, included & & & - & - & - & - & - & - \\
\hline & thymoma & & 44 & - & - & - & - & - & - \\
\hline Rodriguez et al. ${ }^{25}$ & Children $<17 \mathrm{y}$ at onset of & & 149 & $(17)$ & 2.5 & 100 & 77 & 79 & 11 \\
\hline $1983(1932-1976)$ & symptoms treated at $\mathrm{Ma}$ & & 85 & - & - & - & - & 82 & 0 \\
\hline & & No TY & 64 & - & - & - & - & 74 & 26 \\
\hline Oosterhuis $^{26}$ & Referred patients & All & 370 & - & - & 78 & 70 & - & 12 \\
\hline $1981(1960-1980)$ & the Netherland & & 144 & 10.2 & - & - & - & - & 0 \\
\hline & & & 226 & 15.8 & - & - & - & - & 19 \\
\hline Buckingham et al ${ }^{.27}$ & Record review patients at Mayo, & All & 160 & - & 5 & 95 & 80 & - & 2.5 \\
\hline $1976(?-1965)$ & matched for age, gender, severity, & TY & 80 & 19.5 & - & 95 & 80 & - & 2.5 \\
\hline & and duration & No TY & 80 & 23 & - & 95 & 80 & - & 2.5 \\
\hline Emeryk and Strugalska $^{28}$ & Record review cases observed at & All & 187 & 3 & - & 93 & 76 & 63 & 3.6 \\
\hline $1976(1963-1973)$ & Warsaw Department of & $\mathrm{TY}$ & 112 & 3 & - & 95 & 80 & 87 & 1 \\
\hline & Neurology & No TY & 75 & 3 & - & 89 & 69 & 28 & 6.7 \\
\hline Perlo et al. ${ }^{29-31}$ & Record review patients referred to & All & 642 & {$[1-28]$} & 33 & - & - & 51 & 17.7 \\
\hline 1971 & two MG clinics & TY & 225 & - & - & - & 81 & 93 & 0.4 \\
\hline & & No TY & 417 & - & - & - & - & 28.5 & 27.1 \\
\hline Zeldowicz and Saxton ${ }^{32}$ & Vancouver General Hospital, & All & 60 & - & - & 81 & 65 & 53 & 18.3 \\
\hline 1969 & periodic examinations and & TY & 30 & 9 & - & 94 & 87 & 80 & 3.3 \\
\hline & communications with patients & No TY & 30 & 11 & - & 70 & 43 & 27 & 33 \\
\hline Henson et al. ${ }^{33}$ & Patients referred to a large teaching & All & 77 & 7.4 & 3 & 84 & 83 & - & 15.6 \\
\hline $1965(1948-1962)$ & hospital for consideration of TY & TY & 30 & - & - & 94 & 93 & - & 0 \\
\hline & & No TY & 47 & - & - & 77 & 74 & - & 25 \\
\hline Simpson $^{34}$ & Record review national hospital for & All & 357 & - & 8.4 & 94 & 68 & - & 6.2 \\
\hline $1958(1934-?)$ & nervous disease & TY & 258 & - & 4.7 & 99 & 71 & - & 2.7 \\
\hline & & No TY & 99 & - & 18 & 83 & 60 & - & 15 \\
\hline Eaton and Clagett ${ }^{35,36}$ & Record review MG patients & All & 395 & - & - & - & 55 & - & - \\
\hline $1955(1941-1955)$ & referred to Mayo Clinic & TY & 70 & - & - & - & 63 & - & - \\
\hline & & No TY & 325 & - & - & - & 53 & - & - \\
\hline Eaton et al. ${ }^{37}$ & Referred patients, matched cohort & All & 92 & - & - & - & - & - & - \\
\hline $1953(1941-1955)$ & for age, gender, severity, and & TY & 44 & - & - & - & - & - & - \\
\hline & duration of disease & No TY & 48 & - & - & - & - & - & - \\
\hline
\end{tabular}

*Last publication year for cohort

$\dagger$ Percentage with Osserman grade 2B, 3, or 4

$\$$ Percentage with strictly ocular myasthenia. 
Table 3 MG outcomes by cohort survey

\begin{tabular}{|c|c|c|c|c|c|c|c|c|c|c|c|c|c|c|c|c|}
\hline \multirow[b]{2}{*}{ Author year } & \multicolumn{4}{|c|}{ MF remission } & \multicolumn{4}{|c|}{ Asymptomatic } & \multicolumn{4}{|c|}{ Improved } & \multicolumn{4}{|c|}{ Survived } \\
\hline & $\begin{array}{c}\mathrm{NH}, \\
\%\end{array}$ & $\begin{array}{c}\mathrm{TH}, \\
\%\end{array}$ & $\mathrm{RR}$ & $\mathrm{CI}$ & $\begin{array}{c}\mathrm{NH} \\
\%\end{array}$ & $\begin{array}{c}\mathrm{TH}, \\
\%\end{array}$ & $\mathrm{RR}$ & $\mathrm{CI}$ & $\begin{array}{c}\mathrm{NH}, \\
\%\end{array}$ & $\begin{array}{c}\mathrm{TH}, \\
\%\end{array}$ & $\mathrm{RR}$ & $\mathrm{CI}$ & $\begin{array}{c}\mathrm{NH}, \\
\%\end{array}$ & $\begin{array}{c}\mathrm{TH}, \\
\%\end{array}$ & $\mathrm{RR}$ & $\mathrm{CI}$ \\
\hline Christensen et al. ${ }^{10} 1998$ & - & - & - & - & - & - & - & - & - & - & - & - & 56 & 84 & 1.5 & $1.3-1.8$ \\
\hline Evoli et al. ${ }^{11} 1998$ & 10 & 33 & 3.3 & $0.8-13$ & - & - & - & - & - & - & - & - & - & - & - & - \\
\hline Beekman et al. $^{12} 1997$ & 25 & 35 & 1.4 & $0.7-2.7$ & 43 & 39 & 0.9 & $0.5-1.5$ & 80 & 96 & 1.2 & $1.0-1.4$ & - & - & - & - \\
\hline Werneck et al. ${ }^{13} 1996$ & 50 & 25 & 0.5 & $0.2-1.0$ & 60 & 54 & 0.9 & $0.6-1.4$ & 100 & 87 & 0.87 & $\begin{array}{c}0.75- \\
1.0\end{array}$ & 100 & 90 & 0.9 & $0.8-1.0$ \\
\hline Evoli et al. ${ }^{14} 1996$ & 7.7 & 7.7 & 1.0 & $0.2-4.4$ & - & - & - & - & - & - & - & - & - & - & - & - \\
\hline Beghi et al. ${ }^{15,16} 1991$ & 8.0 & 17 & 2.1 & $1.2-3.8$ & - & - & - & - & - & - & - & - & - & - & - & - \\
\hline Mantegazza et al. ${ }^{17,18} 1990$ & 6.1 & 13 & 2.2 & $1.3-3.4$ & 24 & 38 & 1.6 & $1.3-2.0$ & - & - & - & - & - & - & - & - \\
\hline Donaldson et al. ${ }^{19} 1990$ & 8.8 & 26 & 3.0 & $1.2-7.2$ & 28 & 62 & 2.2 & $1.4-3.4$ & - & - & - & - & - & - & - & - \\
\hline Papatestas et al. ${ }^{20} 1987$ & - & - & - & - & 14 & 22 & 1.6 & $1.4-2.0$ & - & - & - & - & 76 & 91 & 1.2 & $1.1-1.2$ \\
\hline Grob et al. ${ }^{21-23} 1987$ & - & - & - & - & 11 & 7.7 & 0.7 & $0.5-1.1$ & 49 & 44 & 0.9 & $0.8-1.1$ & 85 & 51 & 0.6 & $0.5-0.6$ \\
\hline Scadding et al. ${ }^{24} 1985$ & 11 & 25 & 2.3 & $1.0-5.4$ & - & - & - & - & 27 & 70 & 2.6 & $1.6-4.2$ & - & - & - & - \\
\hline Rodriguez et al. ${ }^{25} 1983$ & 34 & 48 & 1.4 & $1.0-2.2$ & - & - & - & - & 63 & 82 & 1.3 & $1.0-1.6$ & 84 & 92 & 1.1 & $1.0-1.2$ \\
\hline Oosterhuis $^{26} 1981$ & - & - & - & - & 20 & 26 & 1.3 & $0.9-1.9$ & - & - & - & - & 95 & 95 & 1.0 & $1.0-1.1$ \\
\hline Buckingham et al ${ }^{.27} 1976$ & 7.5 & 34 & 4.5 & $2.0-10$ & - & - & - & - & 24 & 67 & 2.8 & $1.8-4.3$ & 58 & 87 & 1.5 & $1.2-1.8$ \\
\hline $\begin{array}{l}\text { Emeryk and Strugalska }^{28} \\
1976\end{array}$ & 9.3 & 23 & 2.5 & $1.1-5.4$ & - & - & - & - & 56 & 62 & 1.1 & $0.8-1.4$ & 83 & 91 & 1.1 & $1.0-1.2$ \\
\hline Perlo et al. ${ }^{29-31} 1971$ & - & - & - & - & 17 & 41 & 2.4 & $1.8-3.1$ & 28 & 90 & 3.2 & $2.7-3.7$ & - & - & - & - \\
\hline $\begin{array}{l}\text { Zeldowicz and Saxton } \\
1969\end{array}$ & - & - & - & - & 27 & 84 & 3.1 & $1.7-5.8$ & & & & $1.3-2.8$ & 90 & 99 & 1.1 & $1.0-1.3$ \\
\hline Henson et al. ${ }^{33} 1965$ & 26 & 52 & 2.0 & $1.1-3.6$ & 36 & 65 & 1.8 & $1.1-2.8$ & & 65 & 1.0 & $1.2-3.9$ & 96 & 86 & 0.9 & $0.8-1.1$ \\
\hline Simpson $^{34} 1958$ & 16 & 21 & 1.3 & $0.8-2.2$ & 21 & 34 & 1.6 & $1.1-2.4$ & . & 6 & 1.7 & $1.3-2.3$ & 75 & 83 & 1.1 & $1.0-1.3$ \\
\hline Eaton and Clagett ${ }^{35,36} 1955$ & 6.2 & 17 & 2.7 & $1.2-6.1$ & - & - & - & & 33 & & $\Omega$ & $1.5-2.6$ & 73 & 88 & 1.2 & $1.0-1.4$ \\
\hline Eaton et al. ${ }^{37} 1953$ & 10 & 18 & 1.8 & $0.6-4.9$ & - & - & - & & 44 & 10 & 1.6 & $1.1-2.3$ & 85 & 94 & 1.1 & $1.0-1.3$ \\
\hline
\end{tabular}

$\mathrm{MF}=$ medication-free remission; $\mathrm{NN}=$ natural history, percentage of nonthymectomy patients attaining outcome; $\mathrm{TH}=$ thymectomy history, percentage of thymectomy patients attaining outcome; $\mathrm{RR}=$ relative rate of thymectomy patients compared with nonthymectomy patients attaining outcome; $\mathrm{CI}=95 \%$ confidence interval of relative rates.

too little information on the characteristics of their surgical and nonsurgical subjects to allow speculation on reasons for their different results.

The association between thymectomy and improved outcomes achieved significance in seven of 15 studies describing medication-free remission, in eight of 12 studies describing asymptomatic patients on or off medication, in eight of 13 studies describing improvement, and in four of 13 studies describing survival. No study described a significant negative association between thymectomy and any outcome.

Using the median relative outcome rates of the controlled studies as an estimate of the magnitude of benefit, MG patients undergoing thymectomy were twice as likely to attain medication-free remission, 1.6 times as likely to become asymptomatic, and 1.7 times as likely to improve.

Confounding variables. Although the published controlled studies consistently demonstrated a positive relationship between thymectomy and outcomes, they also consistently demonstrated confounding differences between surgical and nonsurgical groups. Thymectomy patients were often enrolled in their respective cohorts years after their nonthymectomy counterparts. ${ }^{21,25}$ Additionally, with few exceptions, MG patients undergoing thymectomy were younger, more often women, and were more likely to have generalized and severe myasthenia. Younger age and female gender are associated with better MG outcomes ${ }^{15}$. The younger age of the thymectomy patients could have spuriously increased the thymectomy-better outcome association. Generalized and severe MG, by contrast, are associated with worse outcomes. ${ }^{15}$ The worse MG severity patients undergoing thymectomy could spuriously suppress the magnitude of a thymectomy benefit.

Adjusting for confounders. To adjust for these potential confounding variables, when possible we recalculated the relative rates of outcomes within MG patient subgroups. These subgroup calculations allowed us to control for one confounder variable at a time. To control for multiple confounders simultaneously, we looked for studies using a matched design or multivariate techniques.

Controlling for single confounding variables. Several studies provided sufficient data to recalculate relative rates of outcomes within MG patient subgroups. ${ }^{12,17,20,21,25-27,29,32-34}$ Table 4 lists the median change in relative outcome rates within age, gender, and severity subgroups. The positive association between thymectomy and improved outcomes persisted after controlling for each of these variables. However, the magnitude of the thymectomy-improved outcome association changed significantly in several subgroups.

MG severity. We observed a large increase in the magnitude of the thymectomy-improved outcome association within the MG subgroup with more severe disease (defined here by Osserman Class 2b, 3, or 4). As mentioned previously, severe MG patients have worse outcomes when compared with mild MG patients. However, severe MG 

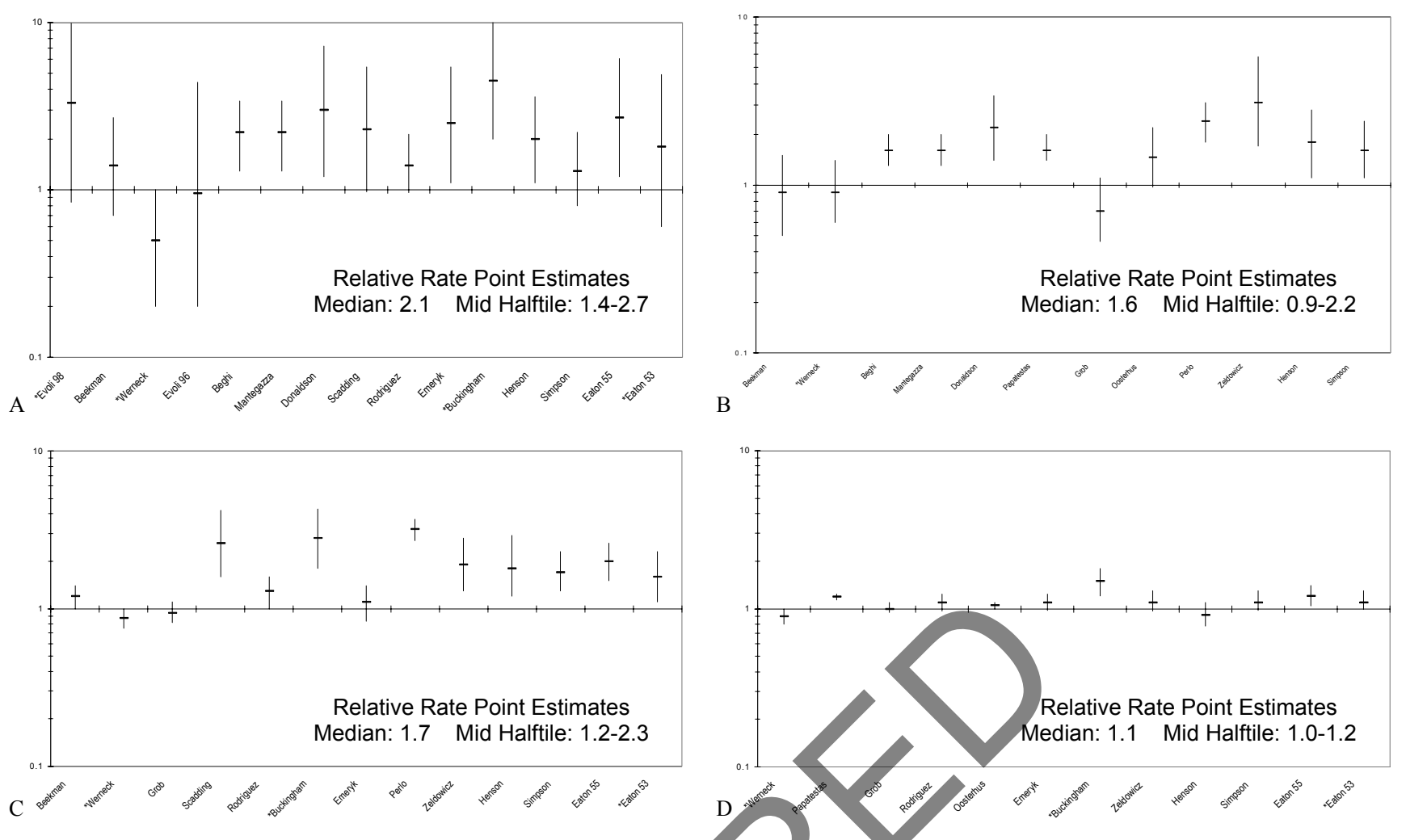

Figure. (A-D) Relative rate of outcomes (with 95\% confidence intervals) in patients with thymectomy compared with patients without thymectomy. (A) Relative rate medication-free remissions. (B) Relative rate asymptomatic. (C) Relative rate improvement. (D) Relative rate survival. Relative rates are plotted on a logarithmic scale. *Matched cohorts. Mid halftile $=25$ th to 50 th percentiles.

patients undergoing thymectomy had larger relative rates of better outcomes when compared with severe MG patients not undergoing thymectomy.

The studies described by Mantegazza et al., ${ }^{17}$ Papatestas et al., ${ }^{20}$ Rodriguez et al., ${ }^{25}$ Perlo et al., ${ }^{29}$ and Zeldowicz and Saxton $^{32}$ allowed the calculation of relative rates within the severe disease subgroup. Relative outcome rates in severe MG patients undergoing thymectomy increased by a median of 54\% $(p<0.01)$ from the relative rate of the entire cohort. For example, in the cohort described by Perlo et al., ${ }^{29}$ severe MG patients undergoing thymectomy were approximately 3.7 times more likely to attain remission than severe MG patients not undergoing thymectomy-a $50 \%$ increase over the relative remission rate of 2.4 of the entire thymectomy cohort described by Perlo et al. ${ }^{29}$

The calculated relative outcome rates within the mild ${ }^{17,20,25,29,32}$ subgroup was not significantly different from the baseline rates.

The association between thymectomy and favorable outcomes was $11 \%$ stronger in the generalized MG patient subgroup (i.e., after excluding ocular patients from the analysis; $p<0.10$ ). ${ }^{12,17,25,26,29,33}$

Age and gender. The studies described by Rodriguez et al., ${ }^{25}$ Buckingham et al., ${ }^{27}$ and Simpson ${ }^{34}$ allowed us to determine relative outcome rates in the male MG subgroup. With the exception of the pediatric myasthenia study by Rodriguez et al., ${ }^{25}$ the male patients were older than the female patients. The relative outcome rate decreased by a median of $25 \%(p<0.05)$ within the male MG subgroup.

The relative outcome rates of the female myasthenia patient subgroup $p^{25,27,33,34}$ were $7 \%$ more than the baseline rates $(p<0.10)$. The relative outcome rates within the younger ${ }^{12,27,34}$ subgroup was not significantly different from the baseline rates.

Year of enrollment. We were also able to control for the patients' year of study enrollment in the studies by Grob et al. ${ }^{21}$ and Rodriguez et al. ${ }^{25}$ In the study by Rodriguez et al., ${ }^{25}$ a 1.4 medication-free remission relative rate persisted in the subgroup seen before 1950, and increased to 1.7 in the subgroup seen after 1950. In the cohort by Grob et al., ${ }^{21}$ the overall cohort's thymectomy relative remission rate of 0.7 increased to 2.2 in the subgroup of patients seen from 1940 to 1957. Thymectomy relative outcome rates were unchanged in the subgroups seen from 1958 to 1965 and 1965 to 1985 .

Medical therapy. None of the studies allowed us to control for the aggressiveness of medical therapies. Thus, we cannot exclude the possibility that MG patients undergoing thymectomy received more aggressive medical therapy than 
MG patients not receiving thymectomy. It is conceivable that we observed a positive thymectomy-favorable outcome association merely because thymectomy was a marker for more aggressive medical therapy.

Controlling for multiple confounders. The preceding subgroup analyses adjusted for differences in one confounding characteristic at a time. In most of the studies reviewed, MG patients undergoing thymectomy differed from patients not undergoing thymectomy by several baseline characteristics. Thus, we looked for studies that attempted to adjust for multiple confounding variables simultaneously. Common mechanisms to compensate for multiple confounders include matched study designs and multivariate analyses. Such adjustments are critical for measuring a benefit from thymectomy when surgical and nonsurgical groups differ in more than one prognostically significant baseline characteristic. ${ }^{6}$

Matched design. Four studies ${ }^{11,13,27,37}$ employed a matched design and attempted to pair thymectomy MG patients with nonthymectomy patients with similar prognostic characteristics including gender, age, severity, and duration of myasthenia. With the exception of the study by Werneck et al., ${ }^{13}$ all of these studies reported positive associations between thymectomy and outcome. However, no study matched patients successfully for all confounding patient characteristics. The studies of both Evoli et al. ${ }^{11}$ and Werneck et al. ${ }^{13}$ failed to match for disease severity. The study of Eaton et al. ${ }^{37}$ did not describe the matching technique employed. In the study by Buckingham et al., ${ }^{27}$ patients receiving thymectomy may have been enrolled many years after patients not receiving thymectomy. Thus, because of unsuccessful matching, these studies are inconclusive.

Multivariate analyses. The studies by Beghi et al., ${ }^{15}$ Papatestas et al., ${ }^{20}$ and Christensen et al. ${ }^{10}$ attempted to control simultaneously for multiple confounding variables by performing a multivariate analysis (Cox proportional hazard model). The study by Christensen et al. ${ }^{10}$ did not measure an independent association between thymectomy and survival after adjusting for baseline characteristics. Papatestas et al. ${ }^{20}$ observed a significant benefit of thymectomy after adjusting for confounding differences in baseline patient characteristics (adjusted relative rate not reported). The adjusted relative rate of attaining medication-free remission after thymectomy calculated by Beghi et al. ${ }^{15}$ did not attain significance (relative rate, $1.6 ; 95 \%$ CI, 0.84 to 3.2 ). Thus, a consistent benefit from thymectomy is not reported in these studies after adjusting for differences in baseline characteristics.

Temporal relationship to remission. Indirect evidence of a thymectomy benefit could be found in a large increase in the proportion of patients attaining medication remission per unit time shortly after thymectomy. Such evidence is provided by the study by Rodriguez et al. ${ }^{25}$ This study of pediatric MG patients reports a spontaneous remission rate of 22.4 per 1,000 person-years, increasing more than 10 -fold to a rate of 260 per 1,000 person-years during the first year after thymectomy. A similar although less dramatic change in remission rates is apparent in the cohort described by Beghi et al., ${ }^{15}$ consisting mostly of adult MG patients.

Alternate explanations for the post-thymectomy changes in remission rates exist, however. Patients selected for thymectomy often receive aggressive $\mathrm{MG}$ medical therapy ${ }^{38}$ in an attempt to prepare them for surgery. The aggressive medical therapy could account for the change in remission rates.

Timing of surgery. Some authors suggest that a thymectomy benefit is realized more readily the earlier thymectomy is performed. ${ }^{39}$ This suggestion is based on the observation of larger remission rates per unit of time in patients undergoing thymectomy earlier after the diagnosis of MG than in those undergoing thymectomy later. This observation can be potentially explained, however, solely on the basis of the nonlinear rate at which MG patients achieve remission after diagnosis. Regardless of thymectomy, for a given duration of time, MG patients are more likely to remit earlier than later. ${ }^{15}$ Under these circumstances any therapy, effective or not, would appear to be more effective if given earlier. ${ }^{6}$

Thymectomy technique. The operative techniques employed in the controlled trials reviewed here either were not identified or consisted of standard transsternal or basic transcervical thymectomies. Some authors assert more aggressive resections, such as transcervical-transsternal maximal thymectomy, are more likely to remove accessory thymic tissue in the neck and mediastinum and result in better outcomes. ${ }^{9}$ This assertion is based on comparisons of remission rates between uncontrolled studies. Outcome comparisons between uncontrolled studies are confounded by differences in patient baseline characteristics in a way similar to that of the nonrandomized controlled trials reviewed here. Additionally, such comparisons introduce other confounders including institutional, geographic, and historical differences in the aggressiveness of medical interventions and outcome assessments that are difficult to control for. ${ }^{7}$ For these reasons, although valuable for hypothesis generation, outcome comparison between uncontrolled studies does not provide conclusive evidence of the superiority of one technique over another. 
The few controlled trials comparing outcomes in MG patients undergoing thymectomy with different surgical techniques demonstrate inconsistent results. The cohorts described by Mantegazza et al. ${ }^{17}$ and Papatestas et al. ${ }^{20,40}$ included patients undergoing transsternal or basic transcervical thymectomies. In both cohorts, subjects undergoing transcervical thymectomy had better outcomes than their transsternal counterparts. In a cohort survey comparing outcomes after simple transsternal, simple transcervical, and extended thymectomy, Masaoka and Monden ${ }^{41}$ observed MG patients who received extended thymectomies had better outcomes. In all of these studies, there were numerous confounding differences between MG patients in each technique group. Thus, controlled trials did not provide convincing evidence that one thymectomy technique was superior.

Thymectomy complications. Eleven of the studies reviewed here reported thymectomy-related mortality. 12,20,21,24,2729,32-35 Perioperative mortality rates were higher in patients undergoing thymectomy before 1970, with commonly reported rates being between 5\% and 15\%. ${ }^{24,27,28,35}$ After 1970, reported mortality rates in the studies reviewed here were consistently less than $1 \%$. Similarly, the mortality of thymectomy in MG patients in most modern uncontrolled series is reported to be less than $1 \% .{ }^{42}$ Common morbidities include acute respiratory failure from crisis in $6 \%$, infection in $11 \%$, and permanent nerve injury (usually the recurrent laryngeal or phrenic nerve) in $2 \%$ of patients. ${ }^{42}$ Lower complication rates are reported with newer thymectomy techniques such as video-assisted thoracic surgery. ${ }^{43}$

Conclusions. After systematically reviewing the controlled but nonrandomized studies describing outcomes in MG patients undergoing and not undergoing thymectomy we found 1) positive associations in most studies between thymectomy and MG remission and improvement (median relative rate of medication-free remission, 2.1; asymptomatic, 1.6; improvement, 1.7); 2) confounding differences in baseline characteristics of prognostic importance between thymectomy and nonthymectomy patient groups in all studies; 3 ) persistent positive associations between thymectomy and improved MG outcomes after controlling for single confounding variables such as age, gender, and severity of MG; and 4) conflicting associations between thymectomy and improved MG outcomes in studies controlling for multiple confounding variables simultaneously. We cannot determine from the available studies whether the observed association between thymectomy and improved MG outcome was a result of a thymectomy benefit or was merely a result of the multiple differences in baseline characteristics between the surgical and nonsurgical groups. Based on these findings, we conclude that the benefit of thymectomy in nonthymomatous autoimmune MG has not been established conclusively.

Practice recommendation. For patients with nonthymomatous autoimmune MG, thymectomy is recommended as an option to increase the probability of remission or improvement (Class II ${ }^{15}$ ).

Recommendations for future research. All currently published studies have serious methodological flaws that prevent definitive conclusions regarding the benefit of thymectomy. These flaws include 1) the absence of randomized allocation to thymectomy and nonthymectomy treatment groups; 2) the absence of standardized, masked outcome determinations; and 3) confounding differences in enrollment year, age, gender, disease duration, and severity in surgical and nonsurgical groups. Because of these serious limitations, a well-designed controlled trial is essential. Such a trial should include:

1. A prospective patient assembly

2. Thymectomy and nonthymectomy treatment groups with different thymectomy technique arms, including extended thymectomy and video-assisted thoracic surgery for thymectomy

3. Randomized assignment to treatment groups or a nonrandomized cohort survey with multivariate adjustments for differences in baseline characteristics between treatment groups

4. Standardization of medical therapies for all patients

5. Rigidly defined and executed evaluation standards ${ }^{44}$ including masked outcome assessments, systematic reporting of treatment complications, quality of life measures, and health care resource usage

If a well-designed, prospective, controlled study demonstrates that thymectomy is beneficial, then future studies could address the timing of thymectomy, which patients benefit most, and the role of other therapies in relation to thymectomy.

Disclaimer. This statement is provided as an educational service of the American Academy of Neurology. It is based on an assessment of current scientific and clinical information. It is not intended to include all possible proper methods of care for a particular neurologic problem or all legitimate criteria for choosing to use a specific procedure. Neither is it intended to exclude any reasonable alternative methodologies. The AAN recognizes that specific patient care decisions are the prerogative of the patient and the physician caring for the patient, based on all of the circumstances involved. 


\section{Acknowledgment}

The AAN thanks Gary Gronseth, MD, and Richard Barohn, MD, for their service to the Academy's membership as authors of this practice parameter. The AAN also thanks the numerous individulas, AAN Sections, and organizations that reviewed drafts of this practice parameter, including: the Muscular Dystrophy Association; Society of Thoracic Surgeons; Myasthenia Gravis Foundation; AB Baker Section; Autonomic Nervous System Section; Government Services Section; Neuromuscular Section; Sleep Section; Spine Section; and Epilepsy Section.

\section{Appendix 1}

American Academy of Neurology Quality Standards Subcommittee Members: Gary Franklin, MD —Co-Chair; Catherine Zahn, MD— Co-Chair; Milton Alter, MD, PhD; Stephen Ashwal, MD; John Calverley, MD; Richard Dubinsky, MD; Jacqueline French, MD; Michael Greenberg, MD; Gary Gronseth, MD (facilitator); Deborah Hirtz, MD; Robert Miller, MD; James Stevens, MD; and William Weiner, MD.

\section{Appendix 2}

Definitions for classification of evidence.

Class I. Evidence provided by one or more well-designed randomized controlled trials, including overviews (meta-analyses) of such trials. studies)

Class II. Evidence provided by well-designed observational studies with concurrent controls (e.g., case-control and cohort

Class III. Evidence provided by expert opinion, case series, and studies with historical controls.

\section{Definitions for strength of recommendations.}

Standards. A principle for patient management that reflects a high degree of clinical certainty (usually this requires Class I evidence that directly addresses the clinical question or overwhelming Class II evidence when circumstances preclude randomized clinical trials).

Guidelines. A recommendation for patient management that reflects moderate clinical certainty (usually this requires Class II evidence or a strong consensus of Class III evidence).

Practice option. A strategy for patient management for which the clinical utility is uncertain (inconclusive or conflicting evidence or opinion).

Practice advisory. A practice recommendation for emerging and/or newly approved therapies or technologies based on evidence from at least one Class I study. The evidence may demonstrate only a modest statistical effect or limited (partial) clinical response, or notable cost-benefit questions may exist. Substantial (or potential) disagreement among practitioners or between payers and practitioners may exist.

\section{References}

1. Blalock A, Mason MF, Morgan HJ, et al. Myasthenia gravis and tumors of the thymic region. Report of a case in which the tumor was removed. Ann Surg 1939;110:544-561

2. Blalock A, Harvey AM, Ford FR, Lilientha JL Jr. The treatment of myasthenia gravis by removal of the thymus gland. Preliminary report. JAMA 1945,127:1089-1096.

3. Blalock A. Thymectomy in the treatment of myasthenia gravis. Report of twenty cases. J Thorac Surg 1944;13:316-339.

4. Lanska DJ. Indications for thymectomy in myasthenia gravis. Neurology 1990;40:1828-1829.

5. McQuillen MP, Leone MG. A treatment carol: thymectomy revisited. Neurology 1977;27:1103-1106.

6. Sackett DL, Haynes RB, Guyatt GH, Tugwell P. Clinical epidemiology: a basic science for clinical medicine. Boston: Little, Brown, 1991.

7. Medawar PB. Induction and intuition in scientific thought. Philadelphia, PA: American Philosophical Society, 1969.

8. Osserman KE. Myasthenia gravis. New York: Grune \& Stratton, 1958.

9. Jaretzki III A. Thymectomy for myasthenia gravis: analysis of the controversies regarding technique and results. Neurology 1997;48(suppl 5):S52-S63.

10. Christensen PB, Jensen TS, Tsiropoulos I, et al. Mortality and survival in myasthenia gravis: a Danish population based study. J Neurol Neurosurg Psychiatry 1998;64:78-83.

11. Evoli A, Batocchi AP, Lino M, Tonali P. Thymectomy for early-onset myasthenia gravis: a case-control study. Neuromuscul Disord 1998;8:270.Abstract.

12. Beekman R, Kuks JBM, Oosterhuis HJGH. Myasthenia gravis: diagnosis and follow-up of 100 consecutive patients. J Neurol 1997;244:112-118.

13. Werneck LC, Cunha FMF, Scola RH. Myasthenia gravis - a study comparing thymectomy, and conservative treatment. Neurology 1996;46:A334.Abstract.

14. Evoli A, Batocchi AP, Tonali P, Palmisani MT, Lino M. Thymectomy for late-onset myasthenia gravis. Neurology 1996;46:A310.Abstract.

15. Beghi E, Antozzi C, Batocchi AP, et al. Prognosis of myasthenia gravis: a multicenter follow-up study of 844 patients. J Neurol Sci 1991;106:213-220.

16. Valli G, Jann S, Premoselli S, Scarlato G. Myasthenia gravis treatment: twelve years experience on 110 patients. Ital J Neurol Sci 1987;8:593-601.

17. Mantegazza R, Beghi E, Pareyson D, et al. A multicentre follow-up study of 1152 patients with myasthenia gravis in Italy. J Neurol 1990;237:339-344. 
18. Scoppetta C, Tonali P, Evoli A, et al. Treatment of myasthenia gravis. Report of 139 patients. J Neurol 1979;222:11-21.

19. Donaldson DH, Ansher M, Horan S, Rutherford RB, Ringel SP. The relationship of age to outcome in myasthenia gravis. Neurology 1990;40:786-790.

20. Papatestas AE, Genkins G, Kornfeld P, et al. Effects of thymectomy in myasthenia gravis. Ann Surg 1987;206:79-88.

21. Grob D, Arsura EL, Brunner NG, Namba T. The course of myasthenia gravis and therapies affecting outcome. Ann NY Acad Sci 1987;505:472-499.

22. Grob D, Brunner NG, Namba T. The natural course of myasthenia gravis and effect of therapeutic measures. Ann NY Acad Sci 1981;377:652-669.

23. Grob D. Course and management of myasthenia gravis. JAMA 1953;153:529-532.

24. Scadding GK, Havard CWH, Lange MJ, Domb I. The long term experience of thymectomy for myasthenia gravis. J Neurol Neurosurg Psychiatry 1985;48:401-406.

25. Rodriguez M, Gomez MR, Howard FM, Taylor WF. Myasthenia gravis in children: long-term follow-up. Ann Neurol 1983;13:504-510.

26. Oosterhuis HJ. Observations of the natural history of myasthenia gravis and the effect of thymectomy. Ann NY Acad Sci 1981;377:678-690.

27. Buckingham JM, Howard FM, Bernatz PE, et al. The value of thymectomy in myasthenia gravis: a computer-assisted matched study. Ann Surg 1976;184:453-458.

28. Emeryk B, Strugalska MH. Evaluation of results of thymectomy in myasthenia gravis. J Neurol 1976;211:155-168.

29. Perlo VP, Poskanzer D, Castleman B, et al. The role of thymectomy in the treatment of myasthenia gravis. Ann NY Acad Sci 1971;183:308-315.

30. Perlo VP, Poskanzer DC, Schwab RS, Viets HR, Osserman KE, Genkins G. Myasthenia gravis: evaluation of treatment in 1,355 patients. Neurology 1966;16:431-439.

31. Schwab RS, Leland CC, Boston AB. Sex and age in myasthenia gravis as critical factors in incidence and remission. JAMA 1953;153:1270-1273.

32. Zeldowicz LR, Saxton GD. Myasthenia gravis: comparative evaluation of medical and surgical treatment. Can Med Assoc J 1969;101:88-93.

33. Henson RA, Stern GM, Thompson VC. Thymectomy for myasthenia gravis. Brain 1965;88:11-28.

34. Simpson JA. An evaluation of thymectomy in myasthenia gravis. Brain 1958;81:112-144.

35. Eaton LM, Clagett OT. Present status of thymectomy in treatment of myasthenia gravis. Am J Med 1955; 19:703-717.

36. Eaton LM, Clagett OT. Thymectomy in the treatment of myasthenia gravis. JAMA 1950;19:963-967.

37. Eaton LM, Clagett OT, Bastron JA. Myasthemia gravis without tumor: comparison of results in surgical and nonsurgical patients. Res Publ Assoc Res Nerv Ment Dis 1953;32:107-112.

38. Seggia JC, Abreu P, Takatani M. Plasmapheresis as preparatory method for thymectomy in myasthenia gravis. Arq Neuropsiquiatr 1995;53:411-415.

39. Monden Y, Nakahara K, Kagotani K, et al. Effects of preoperative duration of symptoms on patients with myasthenia gravis. Ann Thorac Surg 1984;38:287-291.

40. Papatestas AE, Gabriel G, Kornfeld P. Comparison of the results of the transcervical and transsternal thymectomy in myasthenia gravis. Ann NY Acad Sci 1981;377:766-778

41. Masaoka A, Monden M. Comparison of the results of transsternal simple, transcervical simple, and extended thymectomy. Ann NY Acad Sci 1981;377:755-765.

42. Bulkley GB, Bass KN, Stephenson GR, et al. Extended cervicomediastinal thymectomy in the integrated management of myasthenia gravis. Ann Surg 1997:226:324-334.

43. Mack MJ, Scruggs G. Video-assisted thoracic surgery thymectomy for myasthenia gravis. Chest Surg Clin North Am 1998;8:809825 .

44. Jaretzki III A, Barohn RJ, Engel WK, et al. Thymectomy Task Force formed by the Medical Advisory Board of the Myasthenia Gravis Foundation of America. Ann Thorac Surg 1997;64:1311. Letter. 


\title{
Neurology
}

\author{
Practice parameter: Thymectomy for autoimmune myasthenia gravis (an evidence-based \\ review) [RETIRED]: Report of the Quality Standards Subcommittee of the American \\ Academy of Neurology \\ Gary S. Gronseth and Richard J. Barohn \\ Neurology 2000;55;7-15 \\ DOI 10.1212/WNL.55.1.7
}

\section{This information is current as of July 12, 2000}

Updated Information \&

Services

Citations

Permissions \& Licensing

Reprints including high resolution figures, can be found at:

http://n.neurology.org/content/55/1/7 full

This article has been cited by 16 HighWire-hosted articles: http://n.neurology.org/content/55/1/7.full\#\#otherarticles

Information about reproducing this article in parts (figures,tables) or in its entirety can be found online at:

http://www.neurology.org/about/about_the_journal\#permissions

Information about ordering reprints can be found online:

http://n.neurology.org/subscribers/advertise

Neurology $\AA$ is the official journal of the American Academy of Neurology. Published continuously since 1951, it is now a weekly with 48 issues per year. Copyright . All rights reserved. Print ISSN: 0028-3878. Online ISSN: 1526-632X.

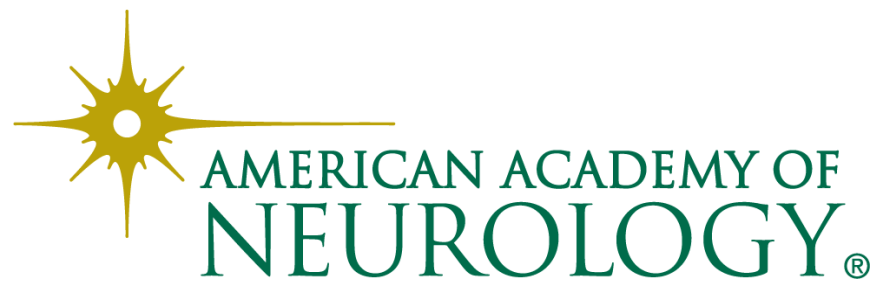




\section{Neurology}

Practice parameter: Thymectomy for autoimmune myasthenia gravis (an evidence-based review) [RETIRED]: Report of the Quality Standards Subcommittee of the American Academy of Neurology

Gary S. Gronseth and Richard J. Barohn

Neurology 2000;55;7-15

DOI 10.1212/WNL.55.1.7

This information is current as of July 12, 2000

Updated Information \&

Services

Citations

Permissions \& Licensing

Reprints including high resolution figures, can be found at:

http://n.neurology.org/content/55/1/7.full

This article has been cited by 16 HighWire-hosted articles: http://n.neurology.org/content/55/1/7.full\#\#otherarticles

Information about reproducing this article in parts (figures,tables) or in its entirety can be found online at:

http://www.neurology.org/about/about_the_journal\#permissions

Information about ordering reprints can be found online:

http://n.neurology.org/subscribers/advertise

Neurology ${ }^{\circledR}$ is the official journal of the American Academy of Neurology. Published continuously since 1951, it is now a weekly with 48 issues per year. Copyright . All rights reserved. Print ISSN: 0028-3878. Online ISSN: $1526-632 X$.

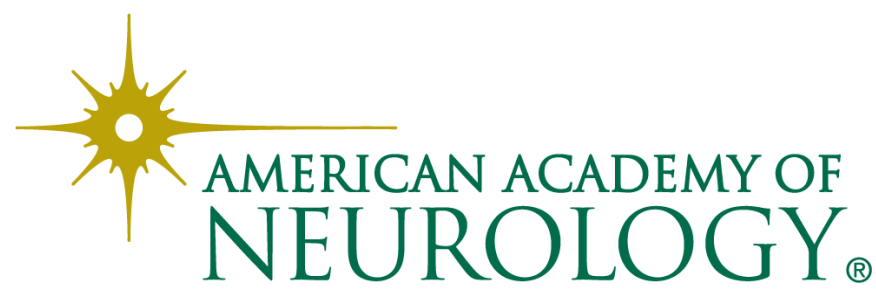

